\title{
Maritime Archaeology and COVID-19
}

\author{
Athena Trakadas ${ }^{1} \cdot$ Annalies Corbin ${ }^{2}$
}

Accepted: 29 January 2021 / Published online: 2 March 2021

(c) The Author(s), under exclusive licence to Springer Science+Business Media, LLC part of Springer Nature 2021

The last 12 months have left an indelible mark on our lives individually and globally. Facing the devastation that has been wrought by COVID-19 means that for too many, a full recovery from the events of 2020 will not be possible. For most, numerous challenges are still posed by restrictions enacted to stem the spread of the pandemic, which will likely continue well into 2021.

Within the field of maritime archaeology, many research trips, conferences and field work projects have been cancelled or indefinitely postponed. Teaching and training endeavours have, for the most part, been held online. Fortuitously, the shift to digital platforms has meant that webinars, lectures, $\mathrm{PhD}$ defences and meetings can still take place, at times with many more participants and geographical representation than prior to the pandemic. However, not everyone has access to sufficient broadband width that can support live streaming of on-line meetings or watch classroom lectures; not everyone has access from home or their place of shelter to online resources for their research. The UN reports that these digital technology issues persisted in the Global South even before the pandemic, and they have only intensified over the last year (International Telecommunication Union et al. 2020). As we experience these disruptions, it is also important to stay aware of such remaining inequities.

$J M A R$ aims to publish articles in the field of maritime archaeology that are globally representative. Over the last decade, the journal has witnessed an increase in submissions from many countries that are still developing national capacities to carry out field work and manage cultural heritage under water and in the coastal zone. As the editors of JMAR, we aim to encourage their submission and support their development for publication. The journal strives to provide a platform where diverse voices, practices and knowledge in our field can be heard and included.

We hope the increase in representation in publication that we have been witnessing will not be too adversely affected by the effects of COVID-19. However, we are likely to see that cultural heritage assets, their study and ultimately their academic publication in regions developing capacity will be impacted (UNESCO 2020; Europa Nostra 2020). Access and action are limited and challenged, as online resources are not accessible and

Athena Trakadas

athena.lynn.trakadas@natmus.dk

Annalies Corbin

annalies@pastfoundation.org

1 National Museum of Denmark, Copenhagen, Denmark

2 PAST Foundation, Columbus, USA 
university and research libraries in many countries remain closed. We must acknowledge this unfortunate reality; in our efforts to be inclusive, we must also remember to continue to address issues of accessibility to information.

Within this challenging year, however, many maritime archaeologists have been able to focus on finishing publications. JMAR received numerous submissions in 2020, which have been expedited relatively quickly through the peer-reviewed process. This positive result of staying home from the field has also coincided with the journal's first year publishing four issues. Past and present, we would like to thank the diverse group of authors who have submitted articles for consideration to JMAR, and the global stable of colleagues who give their time and effort as peer reviewers.

\section{References}

Nostra E (2020) COVID-19 \& beyond. Challenges and Opportunities for Cultural Heritage. Europa Nostra, The Hague

International Telecommunication Union, UNESCO, and UN Children's Fund (2020) The Digital Transformation of Education: Connecting Schools. Empowering Learners, International Telecommunication Union, Geneva

UNESCO (2020) Underwater Cultural Heritage: Professionals grapple with the COVID-19 crisis. 09.06.2020. http://www.unesco.org/new/en/culture/themes/underwater-cultural-heritage/dynamiccontent-single-view/news/underwater_cultural_heritage_professionals_grapple_with_the/. Accessed $1 / 2021$.

Publisher's Note Springer Nature remains neutral with regard to jurisdictional claims in published maps and institutional affiliations. 